\title{
Soft Skills: Education beyond Academics
}

\author{
Dr. Prasanta Kumar Padhi \\ Department of English, Orissa Engineering College
}

\begin{abstract}
Soft skills is a sociological term relating to a person's Emotional Intelligence Quotient, the cluster of personality traits, social graces, communication, language, personal habits, friendliness, and optimism that characterize relationships with other people. Soft skills complement hard skills, which are the occupational requirements of a job and many other activities. A person's soft skill is an important part of their individual contribution to the success of an organization. Particularly those organizations dealing with customers face-toface are generally more successful if they train their staff to use these skills. Screening or training for personal habits or traits such as dependability and conscientiousness can yield significant return on investment for an organization. For this reason, soft skills are increasingly sought out by employers in addition to standard qualifications. Soft skills play a critical role in the career growth of individuals. The expectations begin with the basic foundation of ethics, integrity, and value. Equally non negotiable criteria are a strong work ethic and a professional and positive attitude. In today's job market, employers are not necessarily looking at the most skilled person. If a perfectly skilled job candidate were to come in for an interview and had absolutely no soft skills, the employer may consider looking for some one else. It is completely personal. Soft skills are those nuances that make a person individually unique and stand out. These skills are all about how a person works with others, maintains a positive attitude under pressure, solves a personal or work crisis and communicates both ethically and effectively.
\end{abstract}

Key words: Competency, employability, communication, requirement, personality.

Soft skills are essentially people skills which encompass a wide terrain of personal and interpersonal attributes. They are the complete means of our social, communication, and self-management behaviors. These are the skills that enable us to work effectively and "fit in" at the workplace. It plays an important part in the success of an organization. On the other hand hard skills are technical or administrative procedures related to an organization's core business. These skills are typically easy to observe, quantify and measure. They are also easy to train, because most of the time the skill sets are brand new to the learner and no unlearning is involved. By contrast, soft skills or people skills are typically hard to observe, quantify and measure. People skills are needed for everyday life as much as they are needed for work. They are a set of skills which includes how people relate to each other by communicating, listening, engaging in dialogue, giving feedback, cooperating as a team member, solving problems, contributing in meetings and resolving conflict.

Soft skills play a significant role in one's success in life particularly in one's profession. They help to excel in the workplace and their importance cannot be overlooked in this age of information and knowledge. Ever-increasing global competition and the varying nature of most technical professions have made soft skills more than simply a prerequisite. To employers, technical professionals must not only master their technical disciplines, but also chip in as full participants in accomplishing the mission of the organization. This paper tries to list the skills needed for the professional students to get employed in reputed companies and show how these skills are important for them to work in a performance oriented work environment. It further discusses the mechanisms which can reinforce the students' abilities to secure jobs and retain the same. It discusses how soft skills complement hard skills, which are the technical requirements of a job the student is trained to do. On completion of their course, professional graduates are supposed to step into their career with confidence and should be able to perform as per the expectations of the industry. Modern job selection process is competencybased and professional students are expected to possess those requisite skills and be ready to face the selection process. Embedding the training of soft skills into hard skills courses is a very effective and efficient method of achieving both an attractive way of teaching a particular content and an enhancement of soft skills. Soft skills fulfil an important role in shaping an individual's personality. It is of high importance for every student to acquire adequate skills beyond academic or technical knowledge.

Soft skills in the highly competitive corporate world will help you stand out in a crowd of regular job seekers with ordinary skills and talent. In many technical professions, the sheer focus of education and training is on technical topics related to a career or discipline. Students are generally concerned to master various mathematics skills, science skills and technical skills directly related to the specific disciplines they are planning 
to enter. Though this learning is essential to their success yet the fast-paced and global marketplace of today demands more competencies in soft skills.

Proficiency in soft skills is a mandatory requirement for any professional working in a global business environment. Employers expect the workforce to possess excellent soft skills apart from knowledge and expertise in their respective technical field. In the present day workplace, individuals require a range of occupationally specific knowledge and skills, personal attributes and attitudes, the ability to transfer knowledge and skills to different situations, etc. Another core competency of employees which is the analytical skills or critical thinking is arising as a major concern among employers. Large scale surveys of soft skills reveal that the work force needs have to be constantly upgraded in terms of appropriate skills required. The leaders of industry have reiterated that in this changing milieu, they now seek potential candidates, i.e., graduates with sound technical knowledge as well as efficiency in soft skills. This can be achieved by giving the students adequate and appropriate training in soft skills, so that they are industry-ready and become productive from the day one.

Soft skills are variously viewed as communication skills, interpersonal skills, ability to work with others, and so on. It includes a range of abilities that includes work ethics, courtesy, teamwork, self-discipline and self-confidence, professional presence, language proficiency, cultural sensitivity, communication skills, ability to accept and learn from criticism, ability to handle client relationships, networking, creativity, ability to motive yourself and lead others, time management, leadership and interpersonal skills.

The relative importance of each skill varies by profession. In the IT Services industry communication skills, listening skills, business communication skills, problem solving skills and team skills are perceived as crucial. The BPO sector demands many of these same skill sets. In organized retail, the key skills needed are communication skills, selling skills and customer service skills. This is true for the financial services sector as well.

It is widely acknowledged that India has achieved considerable success in the fields of Information Technology over the past decade. Indian companies have proved that they are competitive in these global industries. In the IT sector, employees at all levels work in an environment in which technical knowledge alone is not enough to create value for the customer or to achieve career progression. Our education system has not prepared our graduates for this work environment. Schools and colleges focus almost exclusively on technical knowledge, and ignore critical areas like industry exposure and soft skills development. This problem has been exacerbated by the need for companies to recruit more candidates from premier institutes, as well as to seek talent at lesser known colleges. In this process students from vernacular medium face career limitations due to their limited English language capabilities, weak communication skills, and poor interpersonal skills.

In all emerging and high growth industries, companies are faced with the need not only find people with the requisite technical skills, but invest heavily in training them in the soft skills that are essential for working with colleagues, customers, suppliers, and with their counterparts across countries and cultures.

There is a lot of argument in the industry as to whether it is possible to enhance soft skills in a few hours of training, especially when one considers the fact that a person has lived with those traits all his life. To this, the answer is harsh but real - a professional who wants to do well in his/ her career does not really have a choice. In the initial years of your career, your technical abilities are important to get good assignments in your workplace. However, when it comes to growing in an organization, it is your personality that matters, more so in large organizations where several people with similar technical expertise will compete for a promotion. Training on soft skills becomes all the more relevant in a country like India where the education system does not delve into personality development. As Sumit Mehta, an eminent research analyst says "Soft skill training is essential because we do not have it in our academic curriculum. Therefore, corporate houses have to take up the task of grooming employees who are the link between the company and the external world, so that they are able to present themselves better "(Nigam, 69).

Training on soft skills becomes more relevant in engineering and management colleges where the education system does not delve into personality development. Soft skills training is essential because we do not have it in our academic curriculum. Therefore, corporate houses have to take up the task of grooming employees who are the link between the company and the external world, so that they are able to present themselves better. Instead of outsourcing the soft skills training it is recommended to bring soft skills within the curriculum. The present English course in the Engineering and management colleges is limited to the communication skills alone. A fine step to enhance the other aspects of soft skills is brought in the curriculum of some technical universities through the introduction of Communication and Interpersonal Skills for Corporate Readiness (CISCR) lab where more thrust is given for role play, group discussion, seminar, presentation, questioning, brain storming, book reviews, interaction etc. This will initially be more challenging by bringing a thorough change in teaching methodology in the existing system that will result in enhancing the skills set of the students and their personality as a professional.

Teachers should react to the changing scenario and equip themselves to meet the need of the hour. Especially, the English teachers, at this crucial juncture, should play a vital role in bridging the gap between 
what is now available in the form of curriculum and the demands of the corporate world. As Cologne states, "we (English teachers) should try to do our best in achieving two results simultaneously that are vital in view of the ever-changing 'face' of English: to enhance our students' linguistic competence; and to prepare them for handling the extra-linguistic demands via soft skills" (p 39).

This transformation can be achieved by moving away from the traditional method of teaching language skills to the communicative method of language teaching. Instead of focusing on grammatical rules, syntactic structures, rote memorization of vocabulary and using literary texts as teaching material, the present-day English teachers need to concentrate on improving language efficiency and soft skills by making use of real life situations as teaching material. For this, a more creative, analytical, logic-oriented and interactive method of teaching should be adopted. In a nutshell, English teachers should become more of a facilitator, and less of an instructor.

The primary purpose of professional institutions is to enhance the capabilities of their students by developing talent, creating knowledge through institutional solutions such as creating digital resources and creative technology solutions for class room learning. The professional students are supposed to work with significant independence and should be strong in leadership qualities. They should have adequate competence to perform the designated duties in effective manner. They should be pro-active and committed and also must be team-players and to have passion for learning at the work site (Sripala, 76). They also need to have capability to leverage the knowledge and promote cross-functional learning (The Hindu Speaks on Education, 2009).

Soft skills are intangible. Only a keen observation can bring out the multifaceted personality of a person over time. These are, therefore, being looked upon as critical traits one needs to have for career growth. Considering the fact that during the last decades the perceived importance of soft skills has increased significantly in society, it is of high importance for everyone to acquire adequate skills beyond academic or technical knowledge. These skills are very essential in the current global job market and are given utmost importance in campus interview. At college level education, it will be a productive venture to incorporate these skills in the syllabus. This will certainly help students develop their employability skills and it will make them execute the assigned works efficiently in any institution after the selection process. The basic philosophy of training of young engineering and management graduates lies in giving information about ground realities and making them the all-round performer. Today, the selection process is different and employer will select the candidates based on how they match the employer's needs. People from different industries are equally keen to recruit students whenever they come across them. It is important for graduates to know what selection attributes are given priority by employers. The technical and management institutions are expected to work as a placement sourcing or a training firm. Naturally the teaching community will have to do the role of a trainer's job apart from teaching .The syllabus has to be designed to enhance the employability skills of the individual candidates and help them to get placed in Multinational Companies. Soft skills fulfill an important role in shaping an individual's personality. It is of high importance for every student to acquire adequate skills beyond academic or technical knowledge to make them employable in their dream jobs.

\section{References}

[1]. Alex, K. "Soft Skills - Know Yourself \& Know the World." S. Chand \& Co, New Delhi, 2010

[2]. Amer, Beverly. Soft Skills at Work: Technology for Career Success. Cengage Learning, Boston, 2009.

[3]. Bolton, Robert. People Skills: How to Assert Yourself, Listen to Others, and Resolve Conflicts. Touchstone, Simon\&Schuster Inc. New York, 1979.

[4]. Cologne, Goeran Nieragden. "The Soft Skills of Business English", The weekly column. (www.eltnewsletter.com/back/September2000/art282000.htm), September 2000.

[5]. Jain, A.K., Pravin, S.R.B., and Sheikh, A.M. "Professional Communication Skills." S. Chand \& Co, New Delhi, 2008.

[6]. Nicolades, Carole. "Focus on Soft Skills: A Leadership Wake-up Call", http://www.businessknowhow.com/growth/softskills.htm, 2002.

[7]. Nigam, Manjari and Ajir Chaturvedi, Importance of Soft Skills \& Emotional Intelligence in Present Scenario, first edition, Global Vision Publishing House, 2010.

[8]. Menon, S. Usha and C. Alamelu, Teaching the Intangibles - The Role of the English Teacher. Language in India: Strength for Today and Bright Hope for Tomorrow. Volume 9 December 2009.

[9]. Sripala, B. "Importance of Soft Skills in Engineering Education." Proceedings of Conference on Soft Skills, JKC College, Guntur, 2011.

[10]. Sripala, B., and G.V. Praveen. "Strategies for Improving Communication Skills for Engineering Students from Rural Background in Andhra Pradesh", 2011.

[11]. The Hindu Speaks on Education. Kasturi \& Sons Ltd, Chennai, 2009.

[12]. Tracey, W.R. The Human Resources Glossary. USA: CRC Press, 2004.

[13]. Wolfe, C. A Psychology of Gesture. Methuen, London, 1984. 